\title{
Optimization of RF signal detection and alert system for restricted area
}

\author{
Ili Najaa Aimi Mohd Nordin', Najla Aiman Nazari' ${ }^{2}$, Muhammad Rusydi Muhammad Razif ${ }^{3}$, \\ Nurulaqilla Khamis ${ }^{4}$, Noraishikin Zulkarnain ${ }^{5}$, Farkhana Muchtar ${ }^{6}$, Nor Aira Zambri ${ }^{7}$ \\ ${ }^{1,3}$ Cybernetics Research Group, Faculty of Engineering Technology, Universiti Tun Hussein Onn Malaysia, Malaysia \\ ${ }^{1,2,3,7}$ Department of Electrical Engineering Technology, Faculty of Engineering Technology, \\ Universiti Tun Hussein Onn Malaysia, Malaysia \\ ${ }^{4}$ Centre for Artificial Intelligence and Robotics, Malaysia-Japan International Institute of Technology, Universiti \\ Teknologi Malaysia, Malaysia \\ ${ }^{5}$ Centre for Integrated Systems Engineering and Advanced Technologies (Integra), Faculty of Engineering and Built \\ Environment, Universiti Kebangsaan Malaysia, Malaysia \\ ${ }^{6}$ School of Computing, Faculty of Engineering, Universiti Teknologi Malaysia, Malaysia
}

\begin{tabular}{l}
\hline \hline Article Info \\
\hline Article history: \\
Received Jan 29, 2019 \\
Revised Apr 28, 2019 \\
Accepted Mar 20, 2019 \\
\hline
\end{tabular}

\section{Keywords:}

Active mobile phone Camera activation Cheating with technology

Multi-band antenna

RF signal detector

\begin{abstract}
This paper presents study on optimizing RF signal detection and alert system for restricted area. Nowadays, mobile phone utilization is very common among youngsters. Despite of being very useful for educational purpose, it turns into a noteworthy issue while being smuggled into restricted area, such as examination hall and used as a cheating tool. To overcome this problem, an advancement on the detection and alert system of active mobile phone was proposed by implementing RF signal detection system optimization using multi-band dipole antenna and alert system utilizing LED and camera. The system demonstrated higher sensitivity to $3 \mathrm{G}$ signal followed by GSM and WiFi with the decrease in voltage value across the LED when distinguishing $3 \mathrm{G}$, GSM and Wi-Fi signal with the estimation of $0.037 \mathrm{~V}, 0.019 \mathrm{~V}$ and $0.017 \mathrm{~V}$, respectively. The alert system was improved by activating LED and camera instead of buzzer in displaying the region of the active mobile phone. The camera was able to effectively capture the conceivable cheating area when active mobile phone is present. The images of the potential cheating region can be recovered from the computer. This framework can assist the invigilators with being cautioned to the potential regions of cheating using mobile phone.
\end{abstract}

Copyright @ 2019 Institute of Advanced Engineering and Science. All rights reserved.

\footnotetext{
Corresponding Author:

Ili Najaa Aimi Mohd Nordin, Cybernetics Research Group, Faculty of Engineering Technology, Universiti Tun Hussein Onn Malaysia Pagoh Campus, Hab Pendidikan Tinggi Pagoh, KM 1, Jalan Panchor, 84600 Pagoh, Johor, Malaysia.

Email: ilinajaa@uthm.edu.my
}

\section{INTRODUCTION}

Examination malpractice can be characterized as a deliberate wrongdoing contrary to the official examination rules and is purposed to place a candidate at an unfair advantage or disadvantage [1-3]. It is also defined as the manner in which candidates can guarantee that they can pass the examination without depending absolutely on their independent ability. There are several types of examination malpractice, for example, impersonation, physical assault, utilization of mercenaries and spying or sneaking. Spying and sneaking are considered as cheating in the examination [2, 4-6]. 
Mobile phone is a great tool that ease and fasten the communication among people from different geographic location. Despite being known as a communication saver, it is these days being utilized unethically to access forbidden material through the electronic notes and web search engine [7-9]. It is also popular for being used to collude with other friends during the examination [6]. $96 \%$ of freshman considered using phone to access online solution manuals during exam as cheating [8]. Year by year, this issue has been making it difficult for the invigilators to keep up the integrity of the examination procedure $[1,3,4,6-8]$.

To prevent the occurrence of cheating using mobile phone, numerous mobile phones detectors and jammers have been invented by researchers in numerous forms of prototype [2, 4, 5, 7, 10-20]. However, some prototypes are constrained to identification of $2 \mathrm{G}$ and GSM network $[4,10]$, thus leaving $3 \mathrm{G}$ and WiFi network uncovered. So as to solve frequency band recognition limitation, an antenna is usually being utilized. The common types of antenna configuration are the microstrip antenna and dipole antenna. Microstrip antenna comprises of patch, substrate and ground plane. This antenna is simple to design, easy to modify according to needs, inexpensive and light-weight. However, it suits low bandwidth and low power application [21]. Another type of antenna is dipole antenna, which usually comprises two straight lines of the same length, lying on the same axis and separated by a small gap [22]. Dipole antenna in [23] has been appeared to have maximum directivity. The directivity is reliant on the antenna length. An antenna of these types can efficiently detect a network, but need to be fabricated in multiple designs to recognize multiple networks. This however can lead to a bulky antenna structure. Other than single dipole antenna, microwave sensor (MS) antenna has also been employed detect multiple networks [13].

Considering that the most recent mobile phones are equipped with various frequency ranges, multiband antenna which can cover the frequency range of GSM, DCS, PCS, UMTS, Bluetooth, WLAN and WiMAX network [22, 24, 25] can be the best candidate to be employed in the detection system of active mobile phone in assisting invigilators during the examination period. Multi-band antenna can be designed using a single printed dipole incorporating Compact Resonant Cell (CRC) structures as CRC structures provide a simultaneous matching for different frequencies [25].

LED and buzzer are certainly the most-frequently possible component being utilized to show the identification of RF signal from mobile phones [2, 4, 5, 10]. Buzzer is an ideal alarming strategy if being used in airport terminal checking station. If it being used in the examination hall, the invigilators can be alerted to the area only when the mobile phone signal occurrence lies within the detector carried by the invigilator. The downside of carrying the mobile phone detector with buzzer as the alerting strategy is that the sounds from the buzzer tends to be a distraction factor to individuals in examination hall. Plus, the potential cheating candidates located far from the detection device can be missed.

In this paper, RF signal detection and alert system advancement is proposed using multi-band antenna and camera. Multi-band dipole antenna was anticipated to be able to identify multiple band RF signals transmitted from other active mobile phones or Wi-Fi routers. Rather than common way of using buzzer to notify the detection of RF signal, camera module OV7670 is proposed to be actualized in the alert system for capturing the scene where the active mobile phone exists. On the off chance that the picture caught demonstrates any type of cheating on mobile phone, it can be used as a proof of cheating in the examination.

\section{RESEARCH METHOD}

This section presents the circuit development of RF signal detection system as the proposed solution from the most recent electronic perspective $[2,4,5,10]$. The first phase of the research includes the improvement of RF identification framework while the second phase is the RF signal alerting framework dependent on image capturing strategy. The process of detection and alert framework when an active mobile is detected can be comprehended based on Figure 1. Multi-band dipole antenna was implemented in the detection framework with camera module OV7670 that results images with resolution of $640 \times 480$ pixels [26] used to capture the images of the scene.

\subsection{RF signal detection circuit}

Figure 2 shows the schematic diagram of detection circuit divided into three sections specifically RF signal transmission receiver for Part A, current to voltage converter for Part B and timer stage for Part C. For RF transmission receiver in Part $\mathrm{A}, 0.22 \mu \mathrm{F}$ ceramic disk capacitor as loop antenna was used to store the energy received from the RF signal detected. In this part, all frequencies including data transmission or RF signal from any call, SMS and Internet network are captured by the capacitors. The most significant component that increases detection sensitivity to various frequency band signals is the antenna. Antenna is the basic component that provides interconnecting links between transmitter and free space or between free space and receiver. In this study, a multi-band dipole antenna was proposed and used to ensure the ability of the detection system to detect signal from various frequency ranges. 

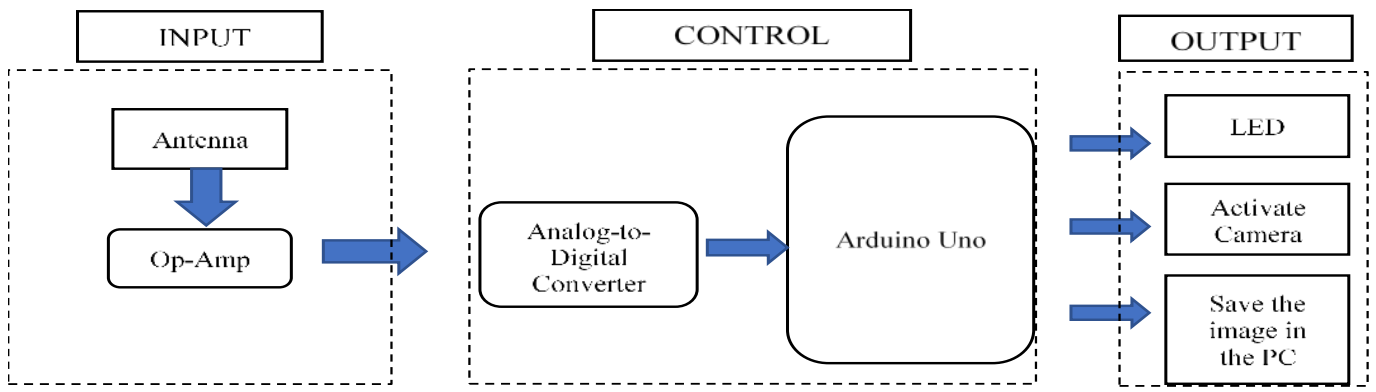

Figure 1. Block diagram of the overall system

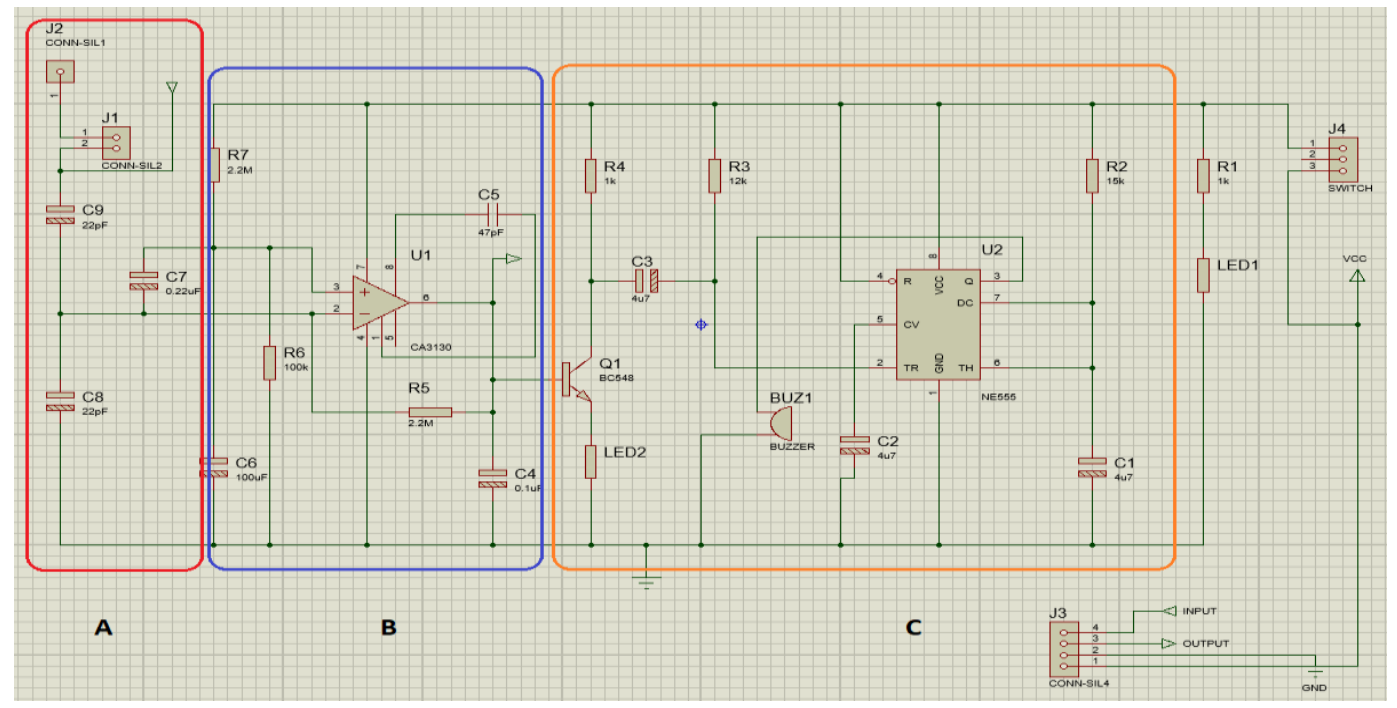

Figure 2. Schematic diagram of the detection circuit

In Part B, current to voltage converter involved CA3130 op-amp for amplifying the fluctuated current from Part A. The fluctuation of current that may go high and low can be observed from LED2 light. CA3130 was used as a differential amplifier for non-inverting input. It acts as current to voltage converter to convert tiny current released by 0.22 capacitor.

A monostable NE555 timer is used as timer stage to trigger the timer and provide an invisible alert concerning the transmission of the mobile data. This timer is controlled by an external resistor and a capacitor. The frequency and duty cycle are accurately controlled by two external resistors and a capacitor with a stable operation. It is used in applications including pulse generation and time delay generation. As the CA3130 is normally off, the NE555 will also be off. When the power is on, CA3130 gives a high output while the BC548 transistor triggers the LED2. LED2 can be a good indicator for the alert system.

To determine the sensitivity of detection system, RF signal test was done in Anechoic chamber, also known as EMC chamber in Electromagnetic Center at UTHM Campus Parit Raja. As shown in Figure 3, anechoic chamber is a special room containing sound-absorbing and sound-attenuating materials in the walls, floor and ceiling to ensure that the room is free from echoes and reverberation.

The sensitivity of circuit indicates the success rate of a faint input signal received by the receiver, which is the detection circuit em-bedded with multi-band. This lab test was conducted using signal generator to supply frequency signal through horn antenna to be received by the detection system. The brightness of LED2 was observed as the result of this test.

\subsection{RF signal alert system image capturing}

The second phase of this study was the improvement of the alert system utilizing Arduino to enact the camera when there is a presence of an active mobile phone in the covered area. Arduino Uno was utilized in this study to switch on the LED blinking, activate the camera and view the image of the scene. To interface between camera module OV7670 with the detection circuit, Arduino Mega 2560 was utilized 
as Analog-to-Digital Converter to convert analog signal from the detection part to digital signal for triggering the activation of camera module. This can be comprehended dependent on Figure 4.

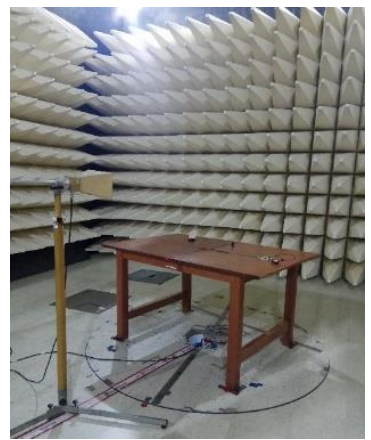

Figure 3. Anechoic chamber

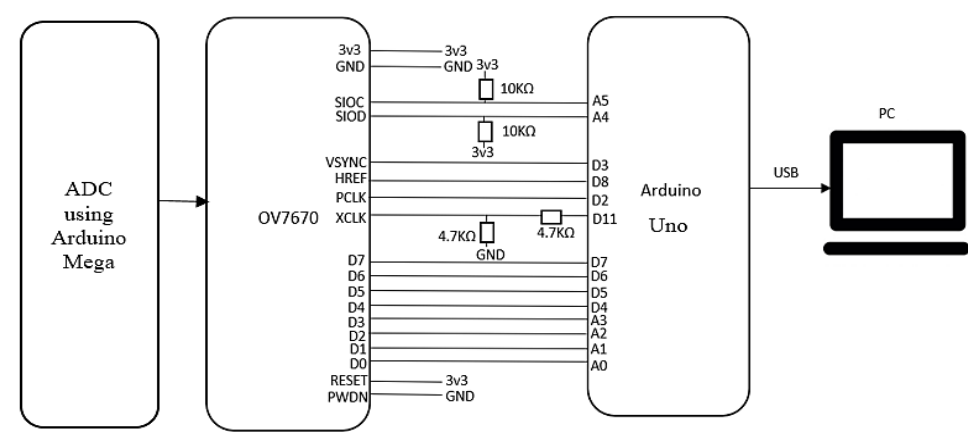

Figure 4. Circuit connection of the alert system

\section{RESULTS AND ANALYSIS}

This section is divided into two segments, RF signal detection and RF signal alert system, which involved camera module OV7670 to automatically capture the image of the scene.

\subsection{RF signal detection system}

Detection circuit was designed using Proteus Design Suite Version 8.0. This software enabled the schematic capture and PCB layout for the detection circuit to be constructed. Figures 5 and 6 demonstrate the PCB layout and PCB physical board of the detection circuit. PCB was used to allow connection of the multi-band dipole antenna with detection circuit to maintain the impedance matching of the antenna.

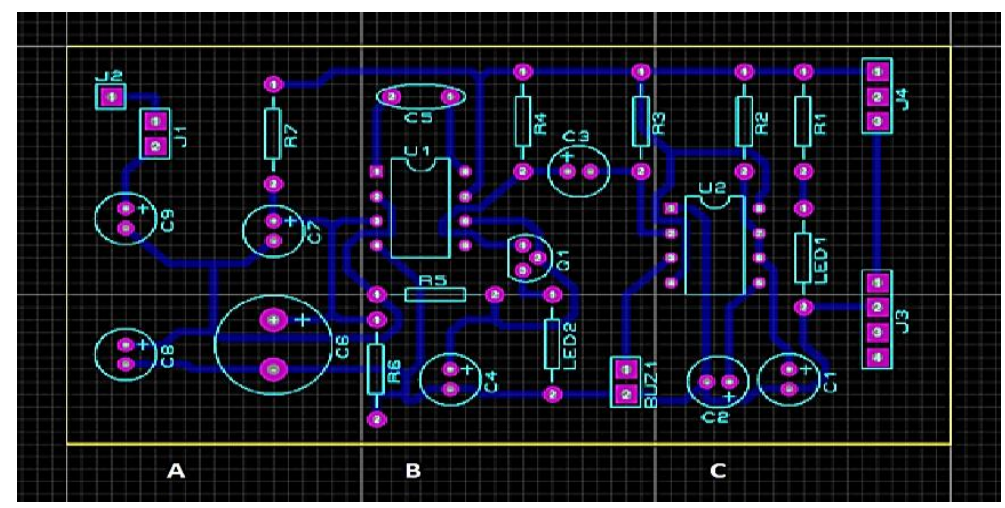

Figure 5. PCB layout of detection circuit

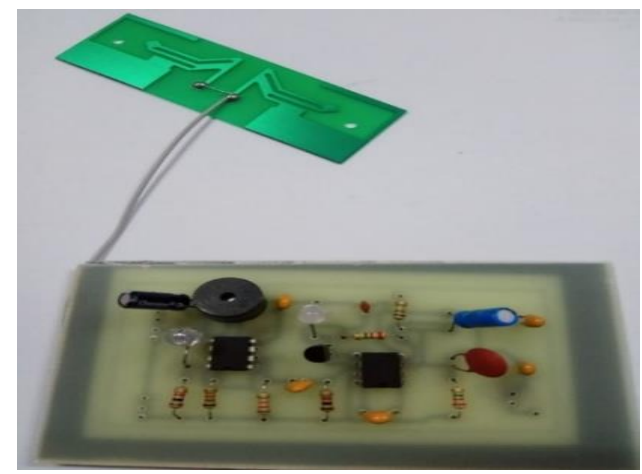

Figure 6. Detection circuit on PCB board 
The sensitivity of detection system was tested for $0,-10$ and $-30 \mathrm{dBm}$ to observe the brightness of LED2 when the detection system received RF signal pumped from the horn antenna to the detection system. Table 1 indicates the results of sensitivity test of RF signal detection system. The brightness and sharpness level of LED2 light was at the highest at input signal frequency of $2.1 \mathrm{GHz}$ (3G signal). The brightness decreases when testing with $1.9 \mathrm{GHz}$ (GSM signal) and $2.4 \mathrm{GHz}$ (Wi-Fi signal). In all cases, LED2 was seen brightly lit without blinking, which means that the signal was fluctuating in a steady state.

Table 1. Sensitivity test for RF signal detection system

\begin{tabular}{|c|c|c|c|}
\hline Frequency $(\mathrm{GHz}) /$ Power $(\mathrm{dBm})$ & $0 \mathrm{dBm}$ & $-10 \mathrm{dBm}$ & $-30 \mathrm{dBm}$ \\
\hline $1.9 \mathrm{GHz}$ & & & \\
\hline $2.1 \mathrm{GHz}$ & & & 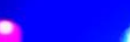 \\
\hline $2.4 \mathrm{GHz}$ & & & \\
\hline
\end{tabular}

In order to interface the detection circuit with the activation of camera module OV7670 as the alert system, the voltage drop of the detection circuit output (LED2) was measured and displayed on Serial Monitor of Arduino IDE. The camera captures image if the voltage is more than or equal to the threshold value, which defined as the average voltage of no network condition.

Figure 7 shows that the maximum voltage during no network condition was at $1.163 \mathrm{~V}$ while minimum of voltage was $0.499 \mathrm{~V}$. The values vary due to the propagation of wave. The average voltage for no network condition was $0.838 \mathrm{~V}$, which was the lowest voltage value compared to other RF signal conditions. For analyzing sensitivity of the circuit to $3 \mathrm{G}$, GSM and Wi-Fi network data transmission, the voltage across LED2 was measured through transmitting signal to a mobile phone located near the detection circuit.

Based on Figure 8, the LED2 voltage values measured were more than $0.838 \mathrm{~V}$ and LED2 was observed lighten up when the mobile phone being observed actively communicating with other mobile phones located far from detection circuit, using $3 \mathrm{G}$ network. Messages were sent to the mobile phone via Gmail and WhatsApp application. This test was conducted at football field to minimize interference from Wi-Fi router signals. The average value of voltage when the detection circuit received $3 \mathrm{G}$ signal was $2.316 \mathrm{~V}$.

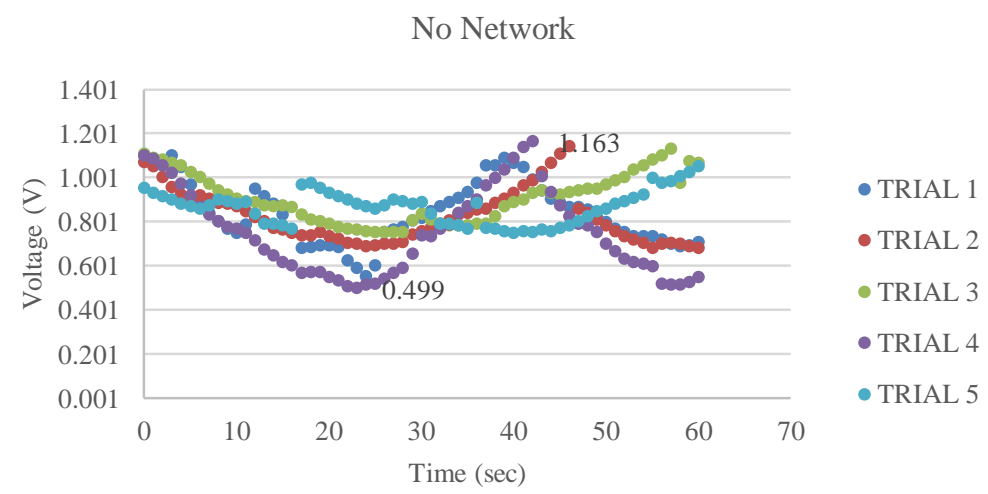

Figure 7. Voltage across the LED when no RF signal is detected 


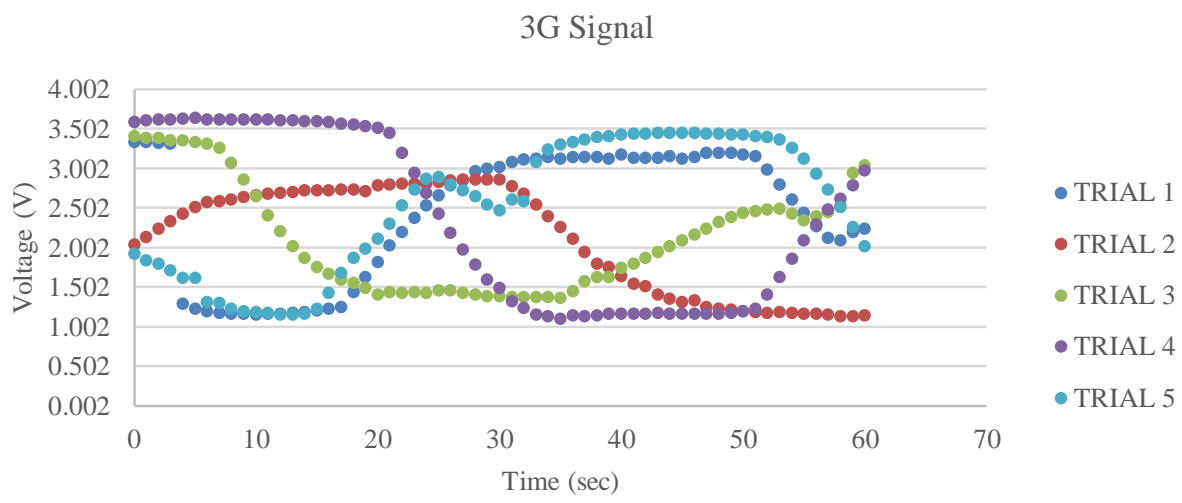

Figure 8 . Voltage across the LED when $3 \mathrm{G}$ signal are detected

Figure 9 shows the voltage value of LED2 when the active mobile phone was transmitting or receiving messages or calls to other mobile phone by using only GSM network. This test was conducted at football field where the existence of $3 \mathrm{G}$ and Wi-Fi signal are minimum. The average voltage value of LED2 for detecting GSM signal was $1.162 \mathrm{~V}$, which is lower than $3 \mathrm{G}$ signal.

Figure 10 presents the voltage values versus time when there was signal only from Wi-Fi connection being detected. This test was conducted at building with non-existence of other active mobile phones, only active Wi-Fi router was present. The results indicated that when Wi-Fi network was used, the average voltage value of the analogue signal was $1.054 \mathrm{~V}$, slightly lower than when detecting GSM signal.

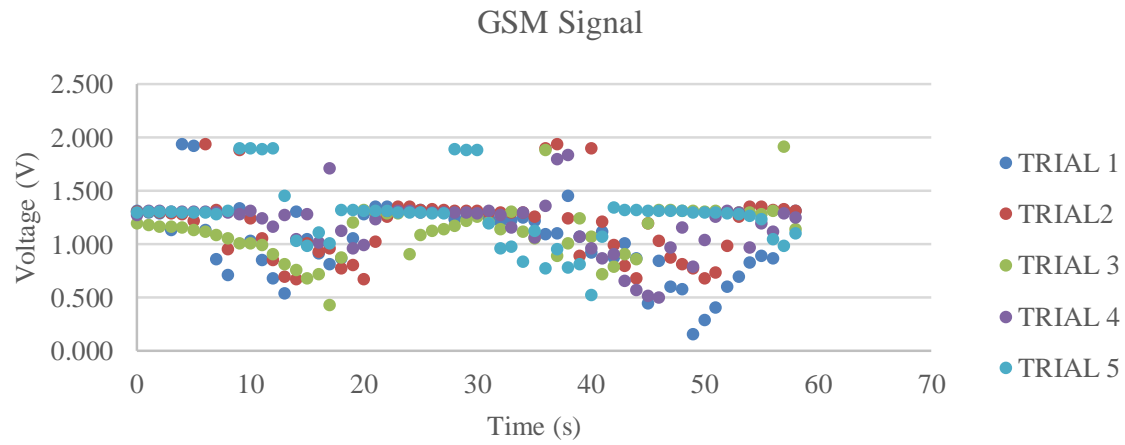

Figure 9. Voltage across the LED when GSM signal are detected

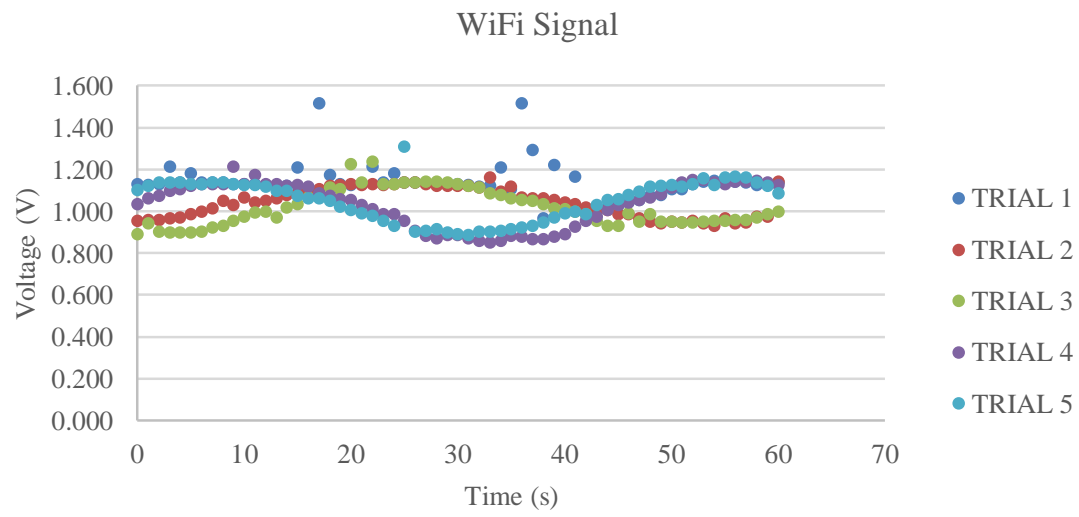

Figure 10. Voltage across the LED when Wi-Fi signal are detected 


\subsection{RF signal alert system}

This study implemented OV7670 camera module to automatically capture image when the detection circuit received RF signal from the active mobile phone. It involved Analog-to-Digital Converter (ADC) using Arduino Mega 2560 to convert analog signal from the detection circuit to digital signal output. The implementation of camera module requires interfacing with Java software.

Figure 11 and 12 demonstrate the results of interfacing OV7670 camera module with Java version 1.8.0 using Command Prompt to capture image automatically and save the image in PC folder C:lout. After Port name COM5 is recognized, the instruction of 'Looking for image' is sent to the camera. Six images being captured by OV7670 camera module were successfully saved in PC in '.bmp' files. Bitmap image files require no graphics adapter to display them and is device independent. This is the reason the output of OV7670 can be saved directly in PC.

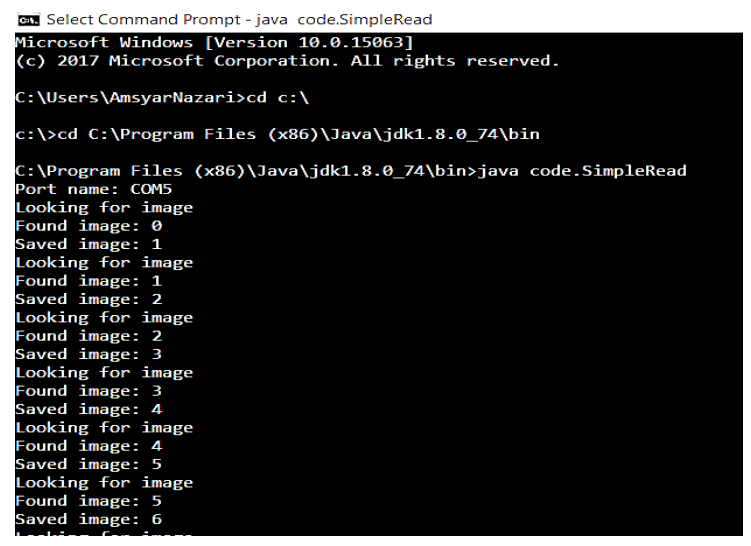

Figure 11. Status of image capturing and storing

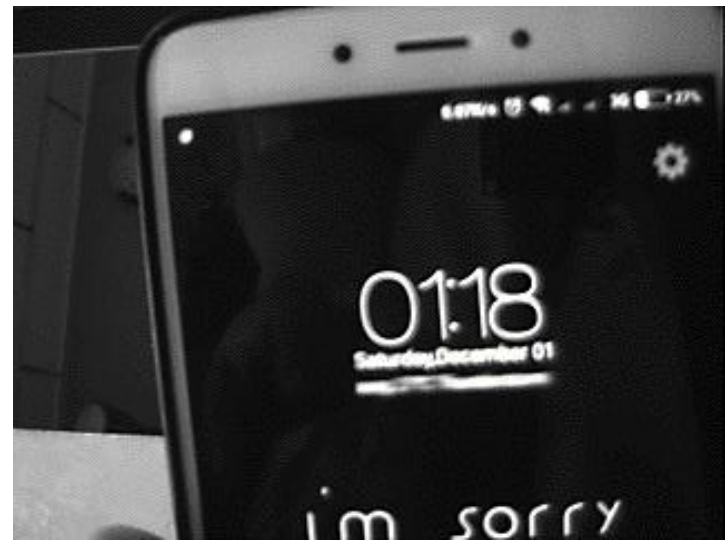

Figure 12. VGA image of camera module

\section{CONCLUSION}

This paper presents an implemention of multi-band dipole antenna in RF signal detection circuit and the capability of the detection system to recognize multiple ranges of RF signals originated from active mobile phone and Wi-Fi router. Futhermore, whenever GSM, 3G and Wi-Fi signals exist, the system can automatically blink the LED and capture image of the scene in real-time. Based on the RF signal sensitivity test experimented at the anechoic chamber lab, at the football field and in a building, the system demonstrates positive outcomes.

In the anechoic chamber, the estimation of circuit sensitivity towards RF signal was done through observing the brightness and sharpness of LED2 light. On the other hand, it was based on recognizing of the input voltage signal that spikes towards LED2 when experimental measurement was conducted at the football field and in the building. In the anechoic chamber, the LED was brightly lit for RF signals projection up to 2meter from the detection circuit. Outside anechoic chamber, RF signals activity was hardly recognized when the mobile phone was placed more than 1.5-meter radius from the antenna. This might be due to diffraction, attenuation, reflection and shadowing of the signal waveform. All in all, regardless of whether inside or outside anechoic chamber, the system comparatively indicates higher sensitivity towards detecting 3G signal, followed by GSM and Wi-Fi signal respectively.

Several recommendations are proposed to enhance the capability and efficiency of the present framework. At present, LED2 showed moderate blink light which can be improved by adding second stage amplifier to increase the current approaches LED2. The detection range can also be extended by utilizing LMV225, a logarithmic amplifier RF power detector, as it is appropriate to intensify signals with wide dynamic range up to $100 \mathrm{~dB}$ from the detection circuit. During conducting the sensitivity test of the circuit in the anechoic chamber, the blink frequency of LED2 can be monitored consequently by utilizing counter as opposed to manual observation which at times can add to errors. Other than sensitivity test, results from receiver bandwidth, reflected power and signal to noise ratio tests can provide additional information in evaluating the performance of the RF detection circuit. An ArduCAM-M-2MP Camera Shield can be a better option for obtaining colored and higher resolution images. Finally, phone detection using automated image analysis [27] can be integrated into the framework and is expected to help the proctoring process by specifically identifying images of candidate with presence of mobile phone. 


\section{ACKNOWLEDGEMENTS}

This research is fully supported by the Tier 1 (H121) grant. The authors are fully acknowledged by the Ministry of Education Malaysia and Universiti Tun Hussein Onn Malaysia for the approved fund which makes this important research viable and effective.

\section{REFERENCES}

[1] S. A. Shariffuddin and R. J. Holmes, "Cheating in Examinations : A Study of Academic Dishonesty in a Malaysian College," Asian J. Univ. Educ., vol. 5, no. 2, pp. 99-124, 2009.

[2] E. Ataro, D. S. Madara, and S. Sitati, "Design and Testing of Mobile Phone Detectors," Innov. Syst. Des. Eng., vol. 7, no. 9, pp. 6-14, 2016.

[3] S. I. Akaranga, P. Jude, and J. Ongong, "The Phenomenon of Examination Malpractice : An Example of Nairobi and Kenyatta Universities," J. Educ. Pract., vol. 4, no. 18, pp. 87-97, 2013.

[4] O. A. O., F. A. S., and A. A. A., "The Design and Implementation of a Mobile Phone Detector Device with a Frequency Jamming Feature," Int. J. Comput. Appl., vol. 143, no. 1, pp. 15-19, 2016.

[5] S. Sitati, D. S. Madara, and E. Ataro, "Design of a Simple Cell-Phone Radio-Frequency Detector," J. Inf. Eng. Appl., vol. 6, no. 7, pp. 13-20, 2016.

[6] D. S. Madara and S. S. Namango, "Faculty Perceptions on Cheating in Exams in Undergraduate Engineering," J. Educ. Pract., vol. 7, no. 30, pp. 70-86, 2016.

[7] K. Curran, G. Middleton, and C. Doherty, "Cheating in Exams with Technology," Int. J. Cyber Ethics Educ., vol. 1, no. 2, pp. 54-62, 2011.

[8] R. Kelley, "The Technology of Cheating," 2014 IEEE Int. Symp. Ethics Sci. Technol. Eng., pp. 1-4, 2014.

[9] A. Sypsas and A. Lekka, "Exploring Secondary Education Teachers' views on Plagiarism and Cheating," in International Conference on Interactive Mobile Communication Technologies and Learning (IMCL), 2014, no. IMCL, pp. 326-330.

[10] C. C. Mbaocha, "Design and Implementation of Intelligent Mobile Phone Detector," Acad. Res. Int., vol. 3, no. 1, pp. 478-483, 2012.

[11] G. Liu, J. Liu, Y. Li, L. Xiao, and Y. Tang, "Jamming Detection of Smartphones for WiFi Signals," in IEEE 81st Vehicular Technology Conference (VTC Spring), 2015, pp. 1-3.

[12] L. Nian-feng, "Study on Mobile Phone Call Monitoring and Positioning and Shielding Algorithms," pp. 1771-1774, 2011.

[13] P. Hudec, M. Polivka, P. Pechac, and S. Member, "Microwave System for the Detection and Localization of Mobile Phones in Large Buildings," IEEE Trans. Microw. Theory Tech., vol. 53, no. 6, pp. 2235-2239, 2005.

[14] M. S. S. Mahat and Dr.S.D.Mundhe, "Proposed Framework : College Attendance Management System with Mobile Phone Detector Abstract :," Int. J. Res. IT Manag., vol. 5, no. 11, pp. 72-82, 2015.

[15] J. Baji, V. Milosavljevi, V. Rajs, M. Slankamenac, and M. Živanov, "Universal Wireless Communication Detector ( UD-100 ) - Preventing of high-tech cheating methods," 2012 Proceedings of the 35th International Convention MIPRO, pp. 237-240, 2012.

[16] A. S. Nyamawe and N. Mtonyole, "The Use of Mobile Phones in University Exams Cheating: Proposed Solution," International Journal of Engineering Trends and Technology (IJETT), vol. 17 , no. 1, Nov 2014.

[17] N. W. Scott, "Study of Cellular Phone Detection Techniques," University of Nebraska, 2011.

[18] Z. Lei, T. Zhongguang, L. Yulong, and W. Tao, "Design of Mobile Phone Security System Based on Detection of abnormal behavior," Int. Conf. Instrumentation, Meas. Comput. Commun. Control, pp. 479-482, 2011.

[19] B. Meneses-claudio, W. Alvarado-Diaz, and A. Roman-Gonzalez, "Design of a Radio Frequency Detection System for Mobile Phones," IEEE 38th Cent. Am. Panama Conv. (CONCAPAN XXXVIII), 2018, pp. 1-5.

[20] A. A. Ajasa, O. Shoewu, and P. O. Nwamina, "Design and Development of a Mobile Phone Signal Detector," Pacific J. Sci. Technol., vol. 15, no. 2, pp. 167-172, 2014.

[21] A. Mehta, "Microstrip Antenna," Int. J. Sci. Technol. Res., vol. 4, no. 03, pp. 54-57, 2015.

[22] M. Zhang, L. Feng, G. Luo, and L. Kui, "A Novel Dual-Band Planar Monopole Mobile Phone Antenna For TD-LTE And TD-SCDMA Applications," in 4th International Conference on Systems and Informatics, 2017, no. ICSAI, pp. $906-910$.

[23] A. Clemente, C. Delaveaud, and L. Rudant, "Analysis of Electrical Dipole Linear Array Maximum Directivity," in 2015 9th European Conference on Antennas and Propagation (EuCAP), vol. 1, no. 1, pp. 1-5.

[24] M. Aminu-baba, M. K. A. Rahim, F. Zubir, and M. F. M. Yusoff, "Design of Miniaturized Multiband Patch Antenna Using CSRR for WLAN / WiMAX Applications," TELKOMNIKA, vol. 16, no. 4, pp. 1838-1845, 2018.

[25] W.-J. Liao, S.-H. Chang, and L.-K. Li, "A Compact Planar Multiband Antenna for Integrated Mobile Devices," Prog. Electromagn. Res., vol. 109, pp. 1-16, 2010.

[26] N. P. Sastra, Wirawan, and G. Hendrantoro, "Virtual View Image over Wireless Visual Sensor Network," TELKOMNIKA, vol. 9, no. 3, pp. 489-496, 2011.

[27] Y. Atoum, L. Chen, A. X. Liu, S. D. H. Hsu, and X. Liu, "Automated Online Exam Proctoring," IEEE Trans. Multimed., pp. 1-16, 2015. 